\title{
BOECIO O LA CADENA DE SABERES. Artes enciclopédicas y teología en la Antigüedad romana
}

La semana del 8 al 12 de junio de 1999 se ha celebrado en la Fundación Singer-Polignac y el Instituto de Francia de París un Coloquio Internacional sobre Boecio, organizado por Alain Galonnier, del "Centre d'Histoire des Sciences et des Philosophies Arabes et Médiévales-U.P.R.E.S.A. 7062" del C.N.R.S. A continuación presentamos un breve resumen de las comunicaciones pronunciadas en este Coloquio, destacando los rasgos -a nuestro juicio- más relevantes de cada exposición. El orden que adoptamos es el que siguieron las propias conferencias.

Thomas Ricklin (Université de Fribourg-Suiza): "Femme-philosophie et homme-animaux: essai de reconstruction de l'imaginaire boécien". En esta conferencia se pone de relieve la importancia de la prosopopeia en la literatura latina de la Antigüedad tardía en tanto fictio personarum, aspecto descuidado en los estudios de Pierre Courcelle. R. estudia las reglas retóricas en la prosopopeia además de otras figuras importantes de concepciones abstractas. Giulio d'Onofrio (Università degli Studi di Salerno): "Boezio filosofo". O. se pregunta: $1^{\circ}$. por el significado de la filosofía en una civilización que, desde Constantino, se reconoce oficialmente como "cristiana"; $2^{\circ}$. por el significado técnico y especulativo de la filosofía dentro de la corriente del neoplatonismo tardío; y $3^{\circ}$. qué pruebas, explícitas o implícitas, pueden extraerse de los textos de Boecio para reconstruir su concepción de la filosofía, y qué relación mantiene con la división de la ciencia y con la clasificación de los ámbitos de conciencia. Graziella Vescovini-Frederici (Univesità degli Studi di Firenze): "L'exorde de l'arithmétique de Boèce et le commentaire de l'averroïste Thaddée de Parme". Tadeo de Parma utiliza el prólogo de la Aritmética de Boecio como introducción general al curso de astronomía que impartía en la Universidad de Bolonia en el 1318. V.-F. pone de manifiesto el "cambio de acento" que se produce en los comentarios de la Aritmética de Boecio del s. XII hasta comienzos del s. XIV. Gaëlle Jeanmart (Université de Liège): "Boèce ou les silences de la philosophie". Para Boecio, el filósofo es capaz de callarse (De Consolatione, I), es decir, parafraseando a Platón, es capaz de poseer algo más valioso que sus discursos orales, y la escritura constituye la práctica meditada y reflexiva de ese silencio (De Consolatione, II). El De Consolatione comienza, precisamente, con una meditación silenciosa. J. se pregunta por la naturaleza de los silencios de Boecio, en qué medida la precaución de Boecio respecto a la capacidad de callarse del filósofo vuelve a cuestionar la dimensión oral de la filosofía, siendo consciente de que, en tanto imitación del discurso oral, la escritura filosófica es dialógica.

Corneille Henri Kneepkens (Rijkuniversiteit Groningen): "God's Providence, Necessity and the Quaestiones Collections on Boethius' Consolation". Las recopilaciones de minor quaestiones sobre el De consolatione de Boecio han inspirado buena parte de la vida intelectual medieval. K. se detiene en el análisis de una colección de minor quaestiones del siglo XV, atendiendo a un tema central de la Consolación: el problema de la providencia divina y la necesidad. Valentin Omelyanchik (Instituto de Filosofía de Kiev): "Boèce et Ammonius sur la question d'Alexandre d'Aphrodisias (Peri hermeneias, 16al-2)". La discusión entre Alejandro y Porfirio respecto al tratado Peri hermeneias de Aristóteles, reconstruida a partir de los comentarios de Boecio y de Ammonio, se reduce a la cuestión siguiente: ¿la aserción es un género común a la afirmación y la negación? O. intenta demostrar, articulando las tesis de Boecio y de Ammonio, que en el origen de esta disputa radica el problema de saber si el enunciado moral es o no un enunciado asertórico simple. O. constata que la posición de Boecio se aproxima más a la de Porfirio, mientras que la de Ammonio sintoniza más bien con la de Alejandro. Aggnieszka Maria Kijewska (Lublin Catholic University): "The Reception of Boethian Methodology in the Middle Ages". La división de las ciencias y la metodología de Boecio fueron adoptadas por los pensadores del s. XII, criticadas por Santo Tomás y retomada en la filosofía de Nicolás de Cusa. K. se centra especialmente en la importancia de las matemáticas como la mejor preparación para la especulación teológica. John Marenbon (Trinity College-Cambridge): "La prescience, le temps et l'éternité dans 
la Consolation de Philosophie". Para Dios, que vive en una eternidad fuera del tiempo, no hay ni pasado ni futuro, todos sus actos tienen lugar en un presente eterno. M. trata de demostrar que Boecio no considera ningún argumento fundado en la necesidad del pasado. Basándose en la lógica modal moderna, M. desarrolla el problema y explica la solución que Boecio parece haber propuesto.

Alessandra di Pilla (Università degli Studi di Perugia): "L'élément de la prière dans la discussion sur la providence et la liberté dans la Consolatio Philosophiae de Boèce". P. analiza los orígenes y el sentido de la concepción de la oración en Boecio, buceando en el problema de su "cristianismo". La negación de la libertad del hombre, consecuencia del reconocimiento de la presciencia divina, se relaciona con la realización necesaria de los acontecimientos futuros. El determinismo universal anula la oración y la justicia en un mundo en que el hombre carece de la responsabilidad de sus acciones. Pero, al mismo tiempo, la oración y la responsabilidad moral son rasgos distintivos del ser humano. Lodi Nauta (University of Groningen): "Boethius' Consolatio Philosophiae in the Renaissance". El latín de Boecio fue considerado como inapropiado desde los paradigmas del latín clásico. Lorenzo Valla criticó el estilo de Boecio, porque contamina perjudicialmente los ámbitos de la filosofía con los de la teología y la literatura. N. analiza la crítica de Valla, y cuál fue la fortuna de la Consolatio entre los comentadores de los siglos XV y XVI. Jean Jolivet (E.P.H.E.-Sciences religieuses): "Quand Boèce aborde Porphyre". J. establece una comparación entre los dos comentarios que Boecio realiza de la Isagogé de Porfirio, precisando los aspectos literarios, léxicos y filosóficos que caracterizan a cada uno de ellos, especialmente en lo que concierne a la introducción y planteamiento de las cuestiones. François Beets (Université de Liège): "Boèce et la sémantique du regard". Cuando intenta dar una solución a las aporías de la omnisciencia y del libre arbitrio en su libro $\mathrm{V}$ del De Consolatione philosophiae, Boecio prefiere una interpretación de la presciencia como visión en lugar de conocimiento racional. Según B., Boecio utiliza el análisis lógico de la predicción -expuesto por Carnéades contra los estoicos, los megáricos y los epicúreos-, para explicar la posibilidad de una presciencia que no implica ninguna necesidad en los acontecimiento futuros.

Béatrice Bakhouche (Université de Montpellier-III): "Le Timée dans l'oeuvre de Boèce". La obra de Boecio aparece jalonada de gran número de referencias indirectas al Timeo de Platón, pero de escasas referencias directas. B. trata de determinar aquello que Boecio conocía del Timeo, en qué contexto utiliza este diálogo, y la función epistemológica que el tratado cosmológico de Platón desempeña en su obra. André Allard (F.N.R.S.-Louvain-La-Neuve): "Sur les nombres figurés et les médiétés dans l'arithmétique de Boèce". En la primera parte, A. describe brevemente los números figurados que aparecen en el De Institutione arithmetica de Boecio; y, en una segunda parte, analiza y describe en profundidad las diez "medietates". Pappus de Alejandría (s. IV) menciona una undécima "medietas", que también la encontramos descrita por Jorndanus Nemoriarius (s. XIII). Claudio Micaeli (Università degli Studi di Pisa): "Il De hebdomadibus di Boezio nel panorama del pensiero tardo-antico". M. trata tres núcleos conceptuales presentes en el De hebdomadibus: 1) el problema de la coincidencia entre lo singular y su esencia; 2) el concepto de similitud; y 3) la coincidencia entre ser y actuar en Dios. El primer problema presenta una afinidad terminológica con el comentario a la Metafísica de Alejandro de Afrodisia, pero aproximándose a la tradición neoplatónica de Plotino y Mario Victorino. Si embargo, Boecio se distingue de ellos porque identifica el Bien primario con el Primer Ser. Respecto al segundo problema, Boecio se relaciona con la teología de san Agustín, y se aproxima a Proclo. Y, los antecedentes del tercer problema se remontan a Porfirio y Mario Victorino. Coloman Viola (C.N.R.S.París): "À la recherche des racines boéciennes de la méthode rationnelle de saint Anselme". V. se pregunta por la influencia de Boecio en la evolución del pensamiento y la metodología de san Anselmo, autor que no cita al autor de la Consolatio. En esta obra puede descubrirse un equivalente de la fórmula anselmiana: aliquid quo nihil maius cogitari possit.

Jean-Yves Guillaumin (Université de Besançon): "Boèce traducteur de Nicomaque: gnomons et pythmènes dans l'Institution arithmétique". Boecio traduce de un modo sorprendente los términos técnicos "gnomon" y "pythmen" del texto griego de Nicómaco, ya que vierte el término griego "gnomon" por el latino fundamentum, que hubiese convenido de modo ideal para traducir "pythmen". G. pone de manifiesto la profunda reflexión de Boecio al realizar su traducción de Nicómaco, en una época tardía que no se ocupa ya mucho de las matemáticas pitagóricas bajo su aspecto técnico. Axel Tisserand (Collège Pontvallain-Sarthe): "Métaphore et translatio in divinis: la question de la connaissance de la nature de Dieu". En De Trinitate (IV) 
la naturaleza de Dios se la considera "una predicción relativa a Dios". La fuente de Boecio son los libros V y VII del De Trinitate de San Agustín, pero su análisis de las categorías aristotélicas recibe claramente una diversidad de influencias. Monika Asztalos (Stockholm Universitet): "Boethius on the Categories". En esta conferencia A. presenta algunos aspectos de su trabajo sobre la edición crítica del comentario boeciano de las Categorías. Se trata del primer proyecto que aborda el texto de Boecio incluyendo un aparato crítico donde se señalan los paralelos con los comentarios de las obras de lógica, sin perder de vista las fuentes utilizadas. Vera Rodrigues (Universidad de Porto): "Thierry de Chartres lecteur du De trinitate de Boèce". El autor del Ephtatheucon otorga un puesto prioritario a las artes del quadrivium y, en particular, a la aritmética, lo que sitúa en un lugar eminente a la opuscula sacra de Boecio. R. parte de un análisis de determinados pasajes del Commentum s. B. De Trin, para tratar de cuantificar el alcance de la influencia boeciana en la elaboración de la doctrina de Thierry, en lo que respecta especialmente al cruce teórico del quadrivium y de la especulación trinitaria.

Michael Bernhard (Bayerische Akademie des Wissenschaften): "Die rezeption der Institutio musica im frühen Mittelalter". En la Alta Edad Media el texto de la Institutio musica recibió una interpretación matemática en el contexto de las.Artes liberales. El sistema de tonos boeciano se cambió en coral para los gregorianos. Michael Lambert (Centre De Wulf-Mansion): "L'analyse statistique comme instrument d'étude des textes médievaux: le problème de l'authenticité des Opuscula sacra”. L. aplica el método de análisis estadístico (estudio de la repartición de categorías gramaticales) a los Opuscula Sacra de Boecio, cuya autenticidad es discutida.

Dominique Bertrand (Institut des Sources Chrétiennes-Lyon): "Sur le fondement de l'altérité dans le De Trinitate: Thomas d'Aquin interprète de Boèce". B. se centra en el comentario de la q. IV, a. 1: "Utrum alteritas sit causa pluralitatie", y se pregunta por el sentido de la afirmación de Boecio. La lectura que realiza Santo Tomás de Boecio en su Super Boehtium de Trinitate. Jean-Luc Solère (C.N.R.S.-París / Université Libre de Bruxelles): "Boèce et Proclus: l'art d'écrire néoplatonicien". La fuente probable del tema de la esfericidad es el Comentario del Timeo de Proclo. S. estudia la metodología neoplatónica, centrándose en las diversas formas de exposición presentes en Boecio.

Lambert Marie de Rijk (Universiteit Maastricht): "Boethius on rhêma and einai (De interpretatione, chap. 3): Is he a reliable guide?". Boecio contribuye indudablemente a la difusión de la lógica aristotélica. Sin embargo, la lógica "aristotélica" se diferencia de la lógica "boeciana". Asimismo, entre la lógica "aristotélica" (silogística tradicional) y la lógica de Aristóteles (Analíticos primeros) hay una serie de contundentes diferencias puestas de manifiesto a partir de Lukasiewicz. R. aborda la concepción boeciana de rhêma y einai, deteniéndose particularmente en las referencias a Aristóteles, reconsiderando la influencia de Ammonio en la interpretación que realiza Boecio. Ubaldo Pizzani (Università degli Studi di Perugia): "Des rapports entre le De musica d'Augustin et le De institutione musica de Boèce". Entre el De musica de san Agustín y el De institutione musica de Boecio hay toda una serie de diferencias y de analogías. P. trata de dar respuesta a una serie de cuestiones: $1^{a}$. ¿disponemos de pruebas que demuestren el conocimiento por parte de Boecio del diálogo de san Agustín sobre la música?; $2^{a}$. ¿Boecio se ha limitado a tratar solamente las doctrinas armónicas con el propósito de acabar la obra de san Agustín, que comprendían seis libros dedicados únicamente al ritmo y a la métrica?; $3^{a}$. ¿es posible establecer puntos de contacto entre las ideas estéticas que se hallan en la base de los dos escritos? Para P. no es posible excluir la existencia de una relación entre los dos tratados, y, aunque se defienda la hipótesis de que Boecio no haya leído el diálogo de san Agustín, las dos obras parecen constituir los dos miembros complementarios de un corpus único. Fabio Troncarelli (Università degli Studi della Tuscia): “Me quoque excellentior' (Consolatio, IV, 6, 37-38). Chi è migliore della Filosofia?". Boecio cita en estas líneas de su Consolatio un texto griego. El estudio léxico de este pasaje pone de manifiesto una serie de influencias del mundo del judeo-cristianismo egipcio de la Antigüedad tardía. T. propone la hipótesis de una serie de rasgos característicos de autores como Orígenes. Umberto Todini (Università degli Studi di Salerno): "Crypto-Christianisme ou retour à Platon: le dernier Boèce". T. se interroga sobre la cuestión de la adhesión última de Boecio al cristianismo en su De Consolatione. La pregunta se planeta no tanto desde un problema de elección entre cripto-cristianismo o cripto-paganismo, sino desde el dictamen de una "voz de crisis", motivado por la presión de acontecimientos biográficos e históricos, que le habría llevado a intentar restablecer la necesidad de una prioridad y de una primacía de la filosofía antigua. 
Paola Paolucci (Università degli Studi di Perugia): "Boèce traducteur de Nicomaque dans le De institutione arithmetica". En esta obra Boecio realiza una traducción literal de la Introducción aritmética de Nicómaco de Gerasa, que constituirá un importante modelo para el filón de traducción científicas de finales de la Edad Media. P. nos llama la atención sobra las "paráfrasis" de Boecio que separan su texto del de Nicómaco. P. extrae del análisis de algunos ejemplos de estas "paráfrasis" la razón subyacente de las omisiones, variaciones e integraciones, atendiendo sobre todo al interés filosófico-científico, y no meramente literario. Sten Ebbesen (Københavns Universitet): "The Metaphysics of Words". En la Antigüedad se necesitan criterios de tipo fonológico y semántico, para determinar lo que constituye una palabra, en tanto opuesta a las no-palabras, a las otras palabras, o a los otros segmentos del discurso (frases, sentencias). E. sitúa esta discusión en la obra de Boecio respecto a sus contemporáneos y predecesores, y señala brevemente los desarrollos posteriores que presenta esta temática.

Christian Meyer (C.N.R.S.-París): "Lectures et lecteurs du De institutione musica au XIII'me siècle". En el siglo XIII decae el interés de filósofos y músicos por el De institutione musica de Boecio. Este declive se debe tanto a la difusión de la filosofía de la naturaleza de inspiración aristotélica, como al desplazamiento de "urgencias teóricas" de los cantos, enfrentados al problema de la notación de la música polifónica. M. se pregunta por aquello que permanece de la enseñanza de Boecio en una musica considerada como ciencia intermedia, situada en la encrucijada de la aritmética y de la física. Michel Lemoine (C.N.R.S.-París/Nouveau Du Cange): "Boèce, modèle du philosophe". L. nos propone la figura de Boecio como el prototipo del filósofo medieval. Gilbert de Poitiers vio en él la unión de la fe católica y del conocimiento filosófico. En la Edad Media Boecio es un autor alabado o ironizado por su intento de conciliar Platón y Aristóteles.

Piotr Smolinski (Lublin Catholic University): "La conception du bonheur dans les Consolations de Boèce et Jean de Tambaco". El De Consolatione theologie de Juan de Tambaco-Johannes Dambach (12881372), perteneciente al círculo de discípulos del maestro Eckhart, se refiere a una tradición consoladora desarrollada en la literatura latina bajo la influencia de Boecio. En el tratamiento de la felicidad, sujeto principal de su obra, Juan de Tambaco considera a Boecio como una autoridad suprema. La obra de Tambaco continúa una tradición boeciana a finales de la Edad Media, y muestra al mismo tiempo cómo ese tipo de literatura agota sus funciones como portadora de la cultura. Max Lejbowicz (Université de Paris-I): “'Cassiodorii Euclides' éléments de bibliographie boécienne". En esta comunicación L. analiza los dos testimonios de Casiodoro en los que se apoya la teoría de una traducción de los Elementos de Euclides por Boecio. Pero hay dos problemas: 1) el texto de los escritos auténticos de Boecio difiere del de los fragmentos euclideanos conservados; 2) Boecio no cita a Euclides en los pasajes en que Boecio habla de sus traducciones; y 3) la traducción de los Elementos hubiera ampliado considerablemente los conocimientos matemáticos de Boecio. John Magee (University of Toronto): "Boehtius'Anapestic Dimetres, with Regard to the Structure and Argument of the Consolatio". Los cuatro poemas de la Consolatio en sus dimetros acatalécticos anapésticos forman un argumento "coherente". I, V = el prisionero, un dilema; III, II y IV, VI = Philosophia; y V, III = el prisionero, un dilema. Hay una correspondencia ente I, V y IV, VI, y este último es una especie de repetición de I, V, pero corrigiendo su dualismo extraño. III, II forma un estadio intermedio de argumentación, que se extiende a I, V y contribuye a IV, VI. V, III constituye la conclusión de la serie, y sitúa al prisionero ante el mismo dilema, como en I, V, pero sin hallarse en el mismo estadio de ignorancia. Anca Vasiliu (C.N.R.S.-París): "Nature et imagine: l'héritage boécien chez Alain de Lille". V. analiza el vocabulario y las definiciones del concepto de "natura", a partir del tratado Contra Eutychès et Nestorius, y, por otra parte, el topos de la alegoría filosófica. Los textos analizados de Lille son las Reglas de teología, el Sermón sobre la esfera inteligible y el Lamento de la Naturaleza. 